\title{
Power, Governance and Agroecology Transformations
}

\begin{abstract}
In this chapter, we focus on issues of power, control and governance in agroecology transformations. Synthesizing the findings across the six domains of transformation introduced in Part II, we explore how the different 'governance interventions' of different actors have multiple effects on a transformative agroecology. Interventions that undermine agroecology have two effects: (i) suppressing agroecology by actively repressing and criminalizing it and (ii) co-opting agroecology by supporting it only to become equivalent to the dominant regime. Interventions that maintain the status quo enable co-existence by (iii) containing agroecology as elements of the dominant regime are strengthened and alternatives ignored and (iv) shielding agroecology from regime dynamics so it is less threatened. In contrast, agroecological transformation of agri-food systems are enabled by (v) processes that support and nurture agroecology to develop on its own terms and (vi) release agroecology from its disabling context by dismantling elements of the dominant regime and anchoring the values, norms and practices of agroecology within and between territories, and at different scales.
\end{abstract}

Keywords Governance • Power • Intervention • Transformation • Social movements

(C) The Author(s) 2021

C. R. Anderson et al., Agroecology Now!, https://doi.org/10.1007/978-3-030-61315-0_10 


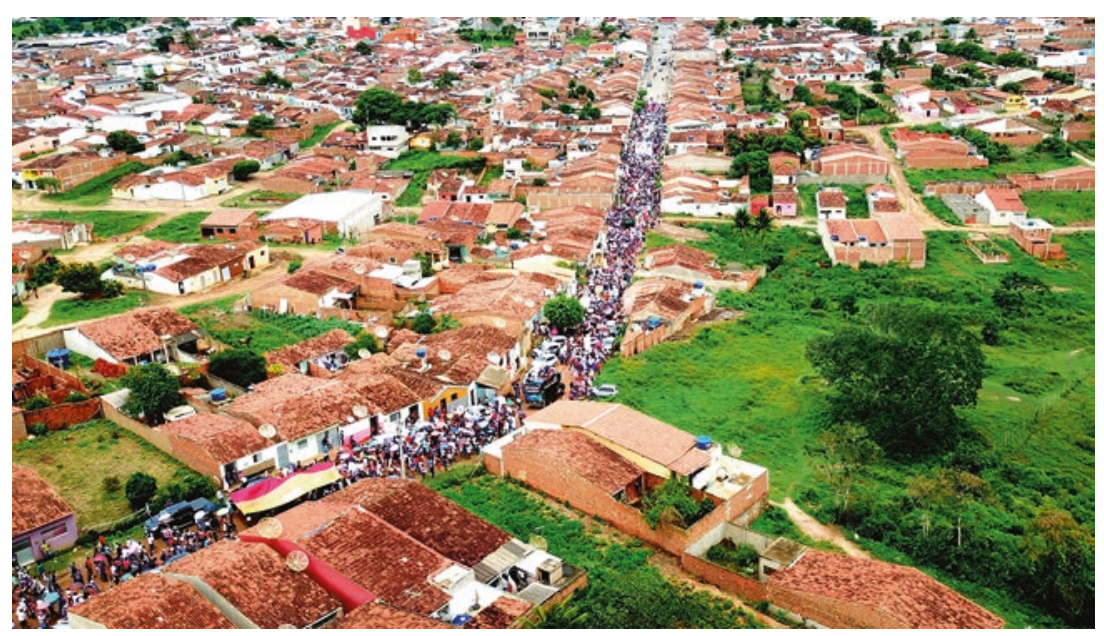

Fig. 10.1 Interventions can influence niche-regime dynamics in each of the domains in different ways. They can:

Strengthen the regime and undermine agroecology by:

Suppressing agroecology by actively repressing and criminalizing it

Co-opting agroecology by supporting it only to become equivalent to regime dynamics/values/norms

Maintain the status quo and enable co-existence by:

Containing agroecology by passively keeping it marginal as regime elements are strengthened and alternatives ignored

Shielding agroecology from regime dynamics so it is less threatened Transform the regime and support agroecology by:

Nurturing agroecology to encourage its strengthening on its own terms Release agroecology from its disabling context by dismantling

Starting from the basis of political agroecology, we looked at each domain to understand the dynamics of power and governance at play in the interface between agroecology and the dominant regime. The conditions in each domain provide an understanding of how change occurshow enabling dynamics are bolstered and disabling ones are deconstructed and replaced. But we need to look at how we get from 'here to there'. Systems-wide transformation can only occur when the power dynamics that support the regime are confronted and when power shifts to excluded actors and groups. Peoples' agency is the crux of agroecology transformations, and it is on this that we now focus.

First, let us look at governance, which is often confused with government. Indeed, many proponents of agroecology work in institutions, governments 
and academia, a world where policy change is often viewed as the primary mechanism of social change. Yet our analysis suggests that it is important to move beyond the notion of policies as a starting point for the scaling of a transformative agroecology. A political agroecology is as much about the process, politics and principles of mobilization and shifting power.

The state-law, policy and regulations specifically-forms an oftenproblematic mechanism in the context of agroecological transformation (Giraldo and McCune 2019; Meek and Anderson 2020; see later section on oppressing and co-opting). Our view, experiences and review of the literature on agroecology transformations indicate that the locus of change from the incumbent regime to a transformative agroecology requires a much broader conceptualization of governance and policy. In any given place (a community, a city, a country, etc.), governance sets rules, rights of access, and the design of economic tools and accountability mechanisms for all actors involved. Governance determines how agroecology is supported as it spreads and how it is strengthened across sectors, regions and countries. Governance is about how power is exercised to take decisions (in communities, families, policy arenas, etc.) or not and who benefits and who does not from the process of change.

The forms of governance that prevail in each of the domains of transformation vary depending on the culture, history and balance of social forces in a particular context. In general, however, in the dominant regime, both the process and the resulting quality of governance will reflect and reinforce the interests of the powerful-be they political parties, elite groups, particular social formations (such as white men), influential families, large transnational corporations or global financial investors. For example, in communities where wages dictate access to food, location dictates access to education, and there are strong traditions of deference to certain types of people (e.g., gentry, men, elders, businessowners), these factors affect who is able to work on social change and participate in government (formal governance) or cultural education, protests and community organizing (informal governance).

Thus, policy is just one governance intervention among many. Other types of governance interventions can include building new market arrangements, learning strategies and decision-making protocols. As such, changes in policy, regulations and law are part of the tactical repertoire in the movement for agroecology transformations and must be approached cautiously and reflexively as a part of a wider set of actions for change. Many interventions, but especially policies, often fail to meaningfully shift power and become transformative-not just those by government but also those by civil society, including NGOs and social movements. 
Elsewhere in this book, we discussed how agroecological transformations are non-linear, context-specific and messy processes that occur in the amorphous space between niche and regime. In this space, governance interventions play a crucial role. There is no single monolithic transformation unfolding in any one place. Indeed, the large-scale transformation of food systems is actually many transformations, in which cultural shifts, policy changes, struggles and networks intervene in complex, dynamic, often contradictory ways. It is vital to develop ways of thinking and working that help to confront, shape, improve and harness the "hopeful monstrosities" (Mokyr 1990 , p. 291, cited in Schot and Geels 2008) that inevitably emerge in the imperfect process of transformation at different scales, places and times.

Our agency-centric approach calls attention to the capacity and necessity for hitherto excluded communities and social movements to build countervailing power and to collectively intervene in the governance of food systems. Fundamental to this process is the recognition that change requires both a diversity of tactics in different spaces and a capacity to be bold and reflexive at the same time. There are a range of ways of working for transformation-different strategies, tactics and theories of changethat cannot be universalized as appropriate or most effective in all possible contexts. What can be universalized is the elevation of social justice, sustainability and well-being as the central aims for governance interventions in agroecology transformations. Further, while we centre our analysis on the ability of collectives to intervene in governance and to exercise influence, we fully recognize that ultimately agroecological transformation cannot be controlled by individual actors or actions and thus transformations must be approached reflexively.

In summary, all these dimensions of power and governance permeate and shape the change that can take place in the domains and thus the quality and validity of agroecological transformations. It is vital to better understand the effects of interventions, in the governance realm of each domain of transformation as they shape the interaction between the regime and the agroecological niche-whether these interventions emanate from formal governments or from civil society.

\section{Six EfFects of Governance Interventions on Agroecological Transformations}

How do different actors, collectives, institutions and governments intervene effectively across the six domains to support lasting and transformational agroecological change? In this section, we deepen the analysis of the 


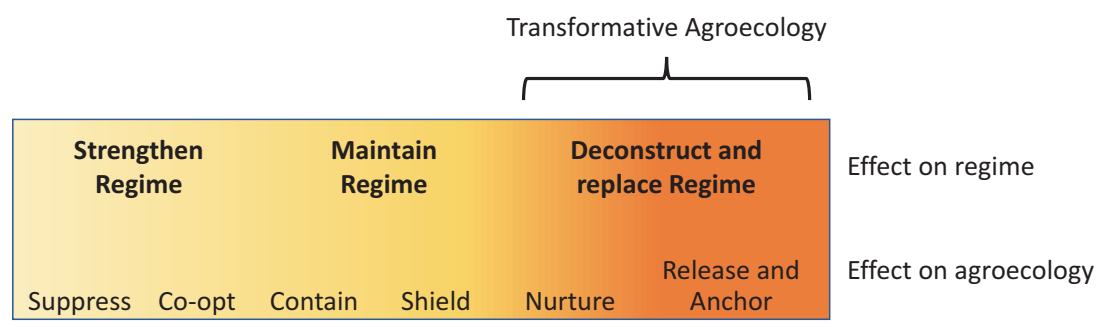

Fig. 10.2 Interventions can influence niche-regime dynamics in each of the domains in different ways

domains by discussing six different effects (Fig. 10.2) that interventions, including policies, can have in relation to agroecology transformations. Since transformation is a complex adaptive process, no one actor can determine it alone or directly by intentional interventions, including those involving financial or state resources. Interventions can, however, increase or decrease the likelihood of directions and outcomes, and sustained or repeated, concerted efforts at particular socio-spatio-temporal junctures make desired transformations much more likely. So, it is important to consider effects that interventions can have on agroecology-and how these may differ in terms of transformational capacity.

This section builds on and provides further nuance to earlier work on the binary between transforming and conforming to the dominant food regime (Levidow et al. 2014). We thus present three effects that undermine agroecology and reinforce the dominant regime (suppressing, coopting and containing) and three that support agroecology transformations (shielding, nurturing and releasing/anchoring). Placing them along a spectrum, it becomes clear that two effects (containing and shielding) represent a middle ground that maintains the status quo and enables the dominant regime and agroecology to co-exist. As we will see, there is a fine line between the various effects, and they can change over time.

Interventions can strengthen the regime and undermine agroecology by:

- Suppressing agroecology by actively repressing and criminalizing it

- Co-opting agroecology by supporting it only to become equivalent to regime dynamics/values/norms

They can maintain the status quo and enable co-existence by: 
- Containing agroecology by passively keeping it marginal as regime elements are strengthened and alternatives ignored

- Shielding agroecology from regime dynamics so it is less threatened

They can transform the regime and support agroecology by:

- Nurturing agroecology to encourage its strengthening on its own terms

- Release agroecology from its disabling context by dismantling elements of the regime and anchor agroecology by replacing these elements with niche dynamics, values, norms and practice

\section{Interventions That Undermine Agroecology and Strengthen the Regime}

\section{Suppressing}

The first of the three types of governance interventions that undermine agroecology involves suppressing people and processes that are favourable to agroecology. This can range from relatively non-violent actions to violent repression and persecution of advocates of agroecology.

Government funding programmes can intentionally bar small-scale producers, women, farmers from lower castes or other agroecological practitioners from government programmes. For example, in the UK Basic Payment Scheme, farmers with under five hectares of land have been ineligible for direct payment subsidies; yet smallholder farmers are key agents of agroecology in Britain and elsewhere. The state may also criminalize processes key to agroecology. For example, the implementation of seed laws that prevent replanting, and trading of farmers' seeds in communities and in peasant seed networks, is a significant impediment to agroecology, leaving food producers dependent on commercial seed suppliers (Goyes and South 2016). Similarly, food safety regulations that make traditional food processing illegal, often with no evidence of any added food safety risk, can stifle agroecology (Wallace 2016; Laforge et al. 2016). And there have been efforts to characterize local exchange and solidary economies, which are essential to agroecology, as a "barrier to trade" (see Chap. 6 on systems of economic exchange). 
Interventions can also more actively dismiss agroecology in the discursive arena (see Chap. 9 on discourse). This has been seen more often in the past five years, in tandem with agroecology's rising profile at the Food and Agriculture Organization of the United Nations (FAO) and in the international community. For example, in a February 2020 speech and again in an August 2020 commentary, Kip Tom, US permanent representative to FAO, claimed that agroecology was responsible for recent locust infestations in Africa. He attacked agroecology, through recurring oversimplifications of the approach as rejecting " $20^{\text {th }}$ century technologies that undergird food security", being 'anti-mechanization' and even intentionally being used by European interests to prevent "progress" in Africa (Tom 2020). Part of Tom's role is advancing US business interests, which are undermined by political agroecology. As he noted towards the end of his speech, his agenda is: "We want to make sure we're delivering value that allows for the free trade of America's products around the world." Similar attacks on agroecology have been made by other industry apologists who have also written op-eds in the farm and popular media.

Suppression can also be physically and brutally violent. Historically, such violence was widely accepted as a basis for colonial expansion-for example, through the dispossession of indigenous and traditional peoples (often historically practising vernacular forms of agroecology) and the installation of colonial monoculture plantation structures and exportfocused, capital-intensive regimes. Today, this violent neo-colonial dynamic is more implicit and is enacted through state-, corporate- and big NGO-sponsored projects and programmes.

Increasingly, activists and land defenders who interfere with state-led and corporate-backed development agendas find themselves victims of such violence. In his 1997 book Green Backlash, Andrew Rowell provided one of the first significant accounts of the tactics through which governments, corporations and authoritarian factions of society actively subverted the environmental movement, in part through direct physical violence against environmental activists, indigenous peoples and other groups. A prominent example is the forced eviction of people from their landthrough land grabs-for private, state or conservation programmes. A more subtle form of violence may take place, when governments and local elites urge resettlement as the only alternative (Milgroom and Spierenburg 2008).

Other interventions that suppress agroecology are the intimidation and murder of ordinary people challenging the dominant regime, demanding 
social justice or defending the environment, the peasantry or rural livelihoods. For example, Global Witness (2018) documented the murder of 207 people in 2017 who stood up to governments and companies-and these are only the documented cases. Their report describes how agribusiness "was the most dangerous sector, overtaking mining for the first time ever, with 46 defenders killed protesting against the way goods we consume are being produced" (Global Witness 2018, p. 8). In some cases, this violence directly involves state actors-police, military or paramilitary forces. In others, private security forces of corporations have carried out the killings while the state acts with indifference towards such violence.

Today, with many national governments exhibiting increasingly authoritarian tendencies, the suppressive effect of the dominant regime is likely to grow. Omar Felipe Giraldo and Nils McCune (2019) detail this in a recent article, noting that "not only have agroecology-friendly policies been overturned in these countries, but they have arguably been converted into tools for repression and information-gathering against movements". One example of this is from the Brazilian programme for the public procurement of food from family farmers (PAA). In the hands of the Temer government (2016-2018), data on cooperatives became a tool for judicial harassment against local farmer organizations, while from 2019 onwards the Bolsonaro administration has been dismantling policies that support agroecology (Borborema 2020) and even shut down the entire Ministry for Agrarian Development-which until then was a key institutional basis for the promotion of agroecology in the country.

Finally, this violence is inflicted not only on people but also on the ecological, cultural and material basis of their identity and livelihoods, further suppressing agroecology. For example, in the mid-2000s in Guatemala, "a boom in environmentally harmful extractive industries brought about by deregulation, World Bank loans to build extractive infrastructure, and increased global demand for land-based resources" (Copeland 2018) led to substantial ecological deterioration, deeply affecting local and indigenous communities. Governance interventions that enact ecological violence, reduce access and undermine rights to nature (including land, seeds, water and ecosystems, as in Domain A (Chap. 4)) —or that facilitate their violent enclosure by large corporate interests-are some of the most debilitating factors for agroecology and agroecology transformations. 


\section{Co-opting}

Governance interventions in any of the domains of transformation can also have the effect of incorporating or co-opting agroecology in ways that encourage conformity to the dominant regime. Rob Raven and Adrian Smith (2012) refer to a "fit and conform" mode of development where radical alternatives in niches, such as agroecology, are subjected to pressure (through incentives) to align with the tenets of the regime. The regime's underlying social, political and ecological processes meanwhile are not substantially affected (also see Levidow et al. 2014). When the actors, policies and mechanisms of the dominant regime take up agroecology it may lead to support, uptake and growth. But there is also the risk that agroecological systems and practices are recast in the mould of the regime and that the social and political forces of agroecology are neutralized and demobilized (van der Ploeg 2018, \#4269; Giraldo and Rosset 2018).

In this respect, many government programmes and other interventions can intentionally or inadvertently appropriate practices, markets and discourse of agroecology, which in their original form were alive with transformative potential. A dynamic of co-optation emerges when interventions to foster agroecology only promote certain incremental changes-those that do not alter power relationships, that support technical fixes in reductionist ways, and that otherwise lack a holistic approach (across all domains) to enable social, cultural, political, economic and ecological dimensions of transitions to sustainable food systems. In other words, agroecology is coopted where funding, support and extension programmes for agroecology bolster actors who already hold power in the dominant system-for example, where public resources for agroecology are allocated to corporate retailers or large farmers (Laforge et al. 2016). Again, this signals the importance assessing of who has power in processes of governance.

In some cases of co-optation, agroecology has been integrated into an actor's language, programmes and policies (e.g. in the case of a state or a development institution), but actual implementation is minimal or only marginally reflects true agroecology transformation. In some parts of Latin America, such as Ecuador, the promotion the principles of agroecology was enshrined in the constitution, yet substantial change in regime configurations - such as a meaningful shift from state support for exportoriented agriculture to peasant farming or agroecology - did not transpire (e.g. Intriago et al. 2017). Another example is the case of France, where 
agroecology has been adopted as a central plank of the Ministry of Agriculture's remit. This has been celebrated but also viewed with scepticism by many of the country's small-scale agroecological producers and others, who have observed that many of the government's programmes reflect a view of agroecology that only involves minor adjustments to an otherwise industrialized system.

Indeed, as Paulo Petersen et al. (2013) warn, the institutionalization of agroecology in government policy often leads to co-optation. It tends to reproduce the top-down approaches characteristic of industrial agricultural development, negating the agency of producers and producers' organizations. According to Stephen Sherwood et al. (2018), this reflects a "scaling up in name but not in meaning": many of the core principles of agroecology are sidelined in favour of ones that are more compatible with the status quo.

This process of co-optation is not only something people and institutions of the regime do to agroecology. It can be a more dispersed and subtle process, often perpetuated by well-meaning researchers governments or NGOs that promote agroecology but seek to mainstream it as a way of scaling it up. They may encourage a technocratic and compromised agroecology to gain institutional uptake (Box 10.1). This dynamic is why social movements and other protagonists of agroecology are putting great efforts into defining a transformative agroecology (Giraldo and Rosset 2018; Anderson et al. 2015) while rejecting diluted interpretations of agroecology that risk undermining their efforts.

The concept of agroecology can also be co-opted within the frame of commercialization and entrepreneurialism in agriculture, where it can be interpreted in conventional, 'regime oriented', ways (Isgren and Ness 2017) or become part of a 'corporate-environmental food regime' (Levidow 2015). For example, agroecological methods, but not necessarily principles, have been adopted by agrochemical companies, some governments and large-scale industrial producers who have incorporated agroecological techniques into 'sustainable intensification' agendas. In Europe, for instance, this nascent neo-productivist agenda selectively incorporates agroecological practices within a toolkit that also includes and promotes biotechnology (Levidow 2015). Such a move and process has been criticized by many farmers' organizations, NGOs and social movements, again reflecting the importance of social movements in contesting co-optation. 


\section{Box 10.1 'Best Policy for Agroecology' in Sikkim-a Deeper Look}

Sikkim won many accolades for becoming the first Indian state to certify all agricultural production as organic by international standards in 2016, including the 2018 Future Policy Award for Best Policy Promoting Agroecology. However, a recent paper shows (Meek and Anderson 2020 ) that while Sikkim's policies may be celebrated as nurturing agroecology, the effects of its governance interventions contradict many of the key ecological, social and political principles of agroecology-especially regarding biodiversity, inclusion, farmer-agency and food sovereignty. "While in some cases the Sikkimese state may be encouraging integrated farming systems, their main thrust is advancing monocultural organic production for export production in a market [led] rather than [a] livelihood led approach" (Meek and Anderson 2020).

The idea of 'Organic Sikkim' is, in principle, congruent with agroecology. But it is a top-down approach that hardly takes account of the traditions, knowledges, genetic resources or the roles of local farmers and citizens, including in the formulation of policies. Yet Sikkim is home to rich agroecological traditions, "knowledges, wisdoms and community dynamics" that have been "an important contributor to food security, biodiversity and well-being and an ongoing field of potential in Sikkim to nurture a just, sustainable and culturally appropriate scaling process" (p. 17).

The government of Sikkim sees small land holdings in the mountains as limiting productivity and market potential. In order to address these perceived constraints, it is imposing new forms of social organization: constructing cooperatives and value chains from the top down. However, these state-led processes tend to benefit those who already hold power and to homogenize the hitherto diverse agricultural landscape to produce volumes of marketable goods and in the end consolidate power and capital and reduce biodiversity. Further, farmers have very little say in these policies, and the political dimensions of agroecology-especially the notion of centring the agency of food producers - are almost completely absent.

This case also highlights how any 'successful' example of agroecology should always be analysed with nuance and depth and it is necessary to evaluate critically to what extent governance interventions actually nurture agroecology. Such an approach helps to demystify the contextualized successes of interventions like Organic Sikkim and what they mean for other places looking to adopt policies for agroecology.

Source: Anderson and Meek (2020) 


\section{Interventions That Maintain the Status Quo and Enable Co-existence}

\section{Containing}

The third disabling effect that governance interventions may have is containing agroecology, or passively keeping efforts to establish it from developing further. While there are a range of 'lock-in' mechanisms that keep the industrial food system in place, these simultaneously 'lock-out' or contain agroecology.

For example, in Chap. 6 (on the systems of economic exchange domain), we discussed how the requirement for standardized, highvolume products in conventional retail chains locks agroecological farmers out of these markets. In Chap. 5 (on the knowledge and culture domain), we showed that the non-recognition of local and traditional knowledge in mainstream science and the narrow economic and productivist basis of indicators marginalize agroecology. Another example is the failure of governments to curtail the concentration and power of corporate retailers, processors and suppliers of external inputs, which drastically contains the potential for agroecology to develop.

Interventions also contain agroecology by enabling actors within the dominant regime to gain yet more access to resources such as funding programmes for large-scale producers. In other instances, containment may arise from food safety regulations designed for large-scale processing and export markets. These are not practically or economically accessible for small agroecological producers or processors; the burden of compliance is only viable when spread across a large-scale operation. Policies or laws, and their implementation, may be inherently biased against women or other non-dominant groups. Those who do not actively take an equitysensitive approach are highly likely to reinforce inequality and power imbalances, containing the emancipatory dimension of agroecology.

Similarly, discourses that position corporations and technology as the protagonists of sustainability transitions-such as in the climate-smart agriculture approach-are often amplified by powerful philanthropists such as the Bill and Melinda Gates Foundation and undermine an agroecology approach that centres the agency of food producers and nature. Support for industrial agriculture by governments, for example through providing subsidies for synthetic fertilizers, can lock farmers into such practices and out of agroecology. All these examples show how 
governance interventions can contain the potential for agroecology to contribute to the transformation towards sustainable food systems while keeping the dominant regime in place (Pimbert 2015).

\section{Shielding}

The first enabling governance intervention is shielding, where policy can help to protect agroecology from the most damaging pressures of the regime without changing the regime itself or directly providing resources to agroecology. As such, it is unlikely to significantly advance agroecology transformations in itself and largely maintains the status quo in terms of transformative potential. Shielding is often introduced through legislative and regulatory exceptions.

In environments where price and convenience are the main criteria for selecting suppliers, small-scale producers are drastically disadvantaged, given the economies of scale and standardization that large corporate food providers can attain. Governments can choose to provide relief, for example in food safety compliance, by not subjecting small-scale agricultural producers to the same requirements as large processors. For example, in British Columbia, Canada, Christiana Miewald et al. (2013) illustrated how important exemptions from industrial food safety standards are for small-scale meat processing: when the exemption was removed, the industry collapsed. Small-scale food producers can also be shielded from imbalanced trade environments through preferential access to institutional food buyers, as was the case with Brazil's School Feeding programme.

Although not specifically targeted at agroecology, green belts can help shield agroecology in peri-urban areas from displacement by development. Legislation that protects peasant and community seed networks and open source intellectual property can protect these important aspects of agroecology from the commercial interests of seed companies (García López et al. 2019). Trade rules that prevent the dumping of cheap imported food, which distorts markets and undermines agroecology, are also an example of shielding.

In essence, shielding is important because it can provide safe spaces for agroecological experiments to mature and protect them from being directly undermined. However, this shielding does little per se to actively enable agroecological transformation. 


\title{
InTERVENTIONS That Support \\ Transformative Agroecology
}

\begin{abstract}
Nurturing
Among transformative governance interventions, the active nurturing of political agroecology - through resources to facilitate the development of agroecological initiatives, networks, markets, innovations and more-is centrally important. Nurturing of agroecology involves support that adheres to the principles of a political agroecology, especially the idea of bolstering the agency of food producers, democratic governance and food sovereignty. In nurturing interventions, the allocation and use of any resources, internally or externally derived, are self-determined by agroecological producers, communities and territorial networks rather than by elite policy-makers or donors.

Nurturing by governments, social movements researchers or other actors involves providing funding, networks or technical support for agroecology initiatives and experiments. These may include cooperative processing schemes; bottom-up and multi-actor networks, platforms and organizations; participatory agroecological research and knowledge exchange; publicity; the development of nested markets; and initiatives that empower women and youth in agriculture. The support is explicitly aimed at enabling agroecology on the terms of its main protagonists. Rarely, but in an ideal case, support structures and priorities from governments and donors are developed through participatory decision-making and guided through the democratic participation of food producers.

In most cases, nurturing is not driven primarily by 'financing' from mainstream institutions and donors but rather is resourced by the social movements, communities and networks that collectively mobilize knowledge, resources and energies at different scales. The global network of agroecology schools supported by the transnational social movement $\mathrm{La}$ Via Campesina (LVC) is a wonderful example of one approach to nurturing. While the resources of the state have been leveraged to some degree, both LVC and the agroecology schools have self-organized in relative autonomy and sometimes opposition to the state.

In the United Kingdom, the work of the Landworkers' Alliance is exemplary, where a young and scrappy union of farmers, growers, foresters and land-based workers grew from a handful of members in the early 2010 s to a powerful organization providing technical and political
\end{abstract}


trainings on agroecology, mutual support networks, mentoring, webbased forums, farmer-led research and more. They also have provided leadership on campaigns to support networks that tackle multiple dimensions of inequity in the food system including gender, racism, immigration and they focus on supporting young farmers. This has also been accomplished through their embeddedness in European and global networks of organizations working to advance food sovereignty and agroecology. This has allowed for the cross-pollination of ideas from different places and also across boundaries, for example in their partnership with allied academic institutions to support their training, research and innovation agenda. The importance of local organizations in nurturing agroecology cannot be understated and further examples can be seen throughout Part II across all regions of the world.

Government involvement in nurturing agroecology generally involves a co-existence approach, where agroecology is intentionally supported by the state through shielding and nurturing but its further development is contained because of the simultaneous, dominant promotion of large-scale, external input-intensive agricultural production. Brazil, India, Nicaragua, Ecuador and a number of other countries are highlighted in the literature as examples where agroecology was supported by state policy, alongside a 'bigger sister' of export-led agriculture. In such cases, even with modest support from the state, small-scale farmers compete on unequal footing because disabling dynamics described in each of the domains are raising barriers (Mier y Terán Giménez Cacho et al. 2018).

The approach of co-existence could be viewed in two ways. On the one hand, it can be seen as creating further space in which agroecology can be strengthened; this could give it more potential to influence and transform the regime. At the same time, this two-tiered approach may represent a way to maintain agroecology as a permanent system next to other dominant systems that emphasize specialization, productivity, scale intensification and narrow technocratic solutions. But in the latter case, agroecology becomes confined or 'niche-ified' as a small sub-sector of agriculture rather than a viable vision for agricultural development.

Civil society is more often the driver in nurturing agroecology, because governmental involvement in it is so often fraught-the result of a sustained struggle and emerging political opportunities, where social movements have been able to anchor agroecology in the dominant regime (see later section on anchoring). Unfortunately, government support and short-term political cycles are not conducive to supporting the long-term 
transformation required for agroecology. Paulo Petersen et al. (2013, p. 111) argue that the "combination of the fragmentation of policies in space (the focus on administrative sectors) and time (the focus on the short term) imposes serious obstacles to the transition of public institutions from the perspective of agroecological development".

There is thus a need to look beyond election cycles and sectoral boundaries to consider a process of trans-local, continuous agroecological development. Nurturing agroecology transformations using the territorial approach (see Section 1: The Territorial Governanceof Agroecology Transformations in Chap. 11) can help to break with the sectoral reductionism that predominates in public policies and many aspects of food systems. Even in the most exemplary cases of governmental support for agroecology, the effects can often be fleeting. Changes in political winds can easily wipe out progress - as we are now witnessing in Brazil, where decades of nurturing agroecology, led by social movements and supported by governments, are being undone.

There is a fine line between nurturing and co-opting. Governance interventions by mainstream actors may appear supportive of a political agroecology, but often they are closely tied to wider economic development trajectories reflecting values of the dominant regime. In this case, programmes for agroecology that appear at first to be enabling may in effect encourage narrowing and specialization (rather than diversification), marketization (orienting towards a market only rather than the multiple functions of agroecology) and technocratic solutions (obscuring the political); they may ultimately leave out the emancipatory dimensions of agroecology (Laforge et al. 2016). Such dynamics can co-opt agroecology. Thus, while the pro-active nurturing of bottom-up forms of agroecology is vital for transformation, equally critical are interventions that directly contest and infiltrate the dominant regime.

\section{Release and Anchor}

Interventions can also have the effect of dismantling the regime to release agroecology from the disabling conditions it creates, while simultaneously anchoring agroecology to the regime, thereby transforming it. To make this possible, overt political contestation of the dominant regime is fundamental. Whereas nurturing is a constructive mode of working, releasing agroecology is deeply deconstructive for the regime. Transformations towards a political agroecology will be impossible if the dominant regime is not extensively gutted, for example by diverting state resources away from 
industrial agriculture towards agroecology or by replacing discourse that favours specialization and exports to one that emphasizes the multifunctionality of agroecology and local and territorial markets.

Efforts to release agroecology address how and why agroecology is contained, co-opted and suppressed-effects 1, 2 and 3 (above)-and instead deconstruct aspects of the regime to make it less hostile to agroecology. It is reflected in the work of social movements, activists, land defenders, critical scholars and investigative journalists that are advancing the material and discursive work of critique, dissent and protest. It is also reflected in campaigns against land grabbing and genetic modification that call out the co-optation of agroecology and fight for the break-up of corporate power in the food chain.

A few examples demonstrate some of these efforts in more detail. In the first example, a range of organizations is actively contesting the corporateled roll-out of a new green revolution for Africa which promotes biotechnology and agri-industry as a solution to food in security in Africa. Recent reports (e.g. Wise 2020) have exposed the failures of these programmes to deliver on the food security outcomes that organizations like the Alliance for a Green Revolution in Africa (AGRA) claim to produce. They also demonstrate the ecological, economic and political downside to the AGRA approach for local peoples, including highlighting the many shortcoming of the first green revolution (in South Asia) as well as unveiling the vested interests of the corporate actors in the global north that finance and champion the green revolution approach.

Elsewhere, successful efforts to ban genetically modified organisms, or glyphosate in municipalities or at a national level, have resulted from the work of social movements in courts, legislatures and on the streets (Peschard and Randeria 2020). These wins are a part of the process of deconstructing the regulatory and legal frameworks that have enabled the encroachment of monocultural chemical agriculture into these territories, thus opening new possibilities for the emergence of alternatives. In another example from Manitoba, Canada, activists mobilized to contest the role of food safety regulations in containing the development of local sustainable food systems, arguing for scale-appropriate regulations and for policy that legitimately supported small farmers to develop agroecological food systems (Laforge et al. 2016).

The other dynamic, anchoring, occurs when niche-regime interactions lead to a durable connection between the two, creating new possibilities for change (Elzen et al. 2012). Anchoring of the niche to the regime can take 
place by establishing new rules or institutions, fostering new practices, processes or technologies, or building new networks and social groups where the tenets of agroecology legitimately infiltrate the regime (Schiller et al. 2019). Anchoring involves the engagement of agroecology proponents, organizations and social movements with the technological, network-related and institutional aspects of the regime. Often, entry points or bridges are found, which allow previously excluded agroecological actors and perspectives to gain access to institutional processes and networks where rules, legislation, discourse, norms and access to finance are negotiated.

Some examples of anchoring can be found at all levels of governance. At the international level, actors have been engaged in a longstanding struggle to anchor agroecology in FAO as an alternative to the dominant focus of a green revolution approach. After a decade of advocacy, negotiations and social movement struggle, FAO launched a global dialogue on agroecology between 2015 and 2018, culminating in the announcement of the Scaling Up Agroecology initiative and the commitment of FAO resources to support agroecology. In this case, a transformative and political agroecology became anchored in one of the most important global public institutions for shaping agricultural research, policy and discourse (Loconto and Fouilleux 2019). Similar work at the global level by social movements can be observed in the efforts to ratify new human rights, for example in the recently adopted declaration of peasant rights or in the Voluntary Guidelines on the Responsible Governance of Tenure of Land, Fisheries and Forests. These global-level anchoring processes create frameworks, mechanisms and resources that actors at local, territorial and national levels can draw on to advance agroecology — for example by holding states accountable to uphold peasants' rights or to implement responsible governance of tenure.

Anchoring can also be viewed in the form of local food policy councils or biodistricts (see Box 11.2 in Chap. 11) which, while varied in their form, can help to foster new markets, regulatory change and other dynamics that anchor agroecology. In their most transformative form, these include participatory dynamics that enable citizens to gain agency in policy-making.

In another example, the research centre where many of the authors of this book are embedded represents a form of anchoring. In 2015, the Centre for Agroecology, Water and Resilience (CAWR) was launched based on a transformative vision of agroecology that brings people's knowledge into dialogue with scientific knowledge in a transdisciplinary approach. CAWR is the largest centre of its kind focusing on agroecology 
and involves approximately 100 members including research staff, students and a support team. The centre has gone on to engage in and advocate for farmer-led, transdisciplinary and participatory approaches to research and food system governance and to focus on enabling agroecology in different territories.

Whereas many contributors to the multi-level perspective literature are rather sanguine about the potential of these anchoring processes, proponents of a political agroecology have been much more cautious and critical as they enter into these institutional spaces. Indeed, while these certainly can contribute to a transformative agroecology, anchoring processes can-like nurturing - also lead to compromises and concessions and ultimately morph into co-optation. This dynamic can be viewed in all of the examples provided in the preceding paragraphs, where the gains made by anchoring agroecology have been accompanied by dynamics (in FAO, in local policy councils and in research centres like CAWR) that reflect aspects of the dominant regime and that do little to substantially shift power. Transformations, again, are not linear and the dominant actors in intergovernmental institutions, local councils and academia-like in all spaces_-adapt to claim back power and to supress and contain efforts to anchor agroecology.

All of these examples highlight the dialectic and non-linear process of transformation and the challenge of anchoring agroecology in the regime. In the next chapter we will discuss how continuous reflection on the effects of any intervention is key to ensure a transformative agroecology and how this is best done by the key actors of a given agroecological territory in participatory processes.

\section{REFERENCES}

Anderson, C. R., Pimbert, M., \& Kiss, C. (2015). Agroecology as Practice, Movement and Vision. https://www.youtube.com/watch?v=-Km9Kv5 UylU\&feature=youtu.be

Borborema, H. (2020). Bolsonaro veta quase todos os artigos do projeto de lei de apoio à agricultura familiar. Available: https://agroecologia.org.br/ 2020/08/25/bolsonaro-veta-projeto-de-lei-de-apoio-a-agricultura-familiar/.

Copeland, N. (2018). Meeting Peasants Where They Are: Cultivating Agroecological Alternatives in Neoliberal Guatemala. The Journal of Peasant Studies, 46(4), 831-852.

Elzen, B., van Mierlo, B., \& Leeuwis, C. (2012). Anchoring of Innovations: Assessing Dutch Efforts to Harvest Energy from Glasshouses. Environmental Innovation and Societal Transitions, 5, 1-18. 
García López, V., Giraldo, O. F., Morales, H., Rosset, P. M., \& Duarte, J. M. (2019). Seed Sovereignty and Agroecological Scaling: Two Cases of Seed Recovery, Conservation, and Defense in Colombia. Agroecology and Sustainable Food Systems, 43(7-8), 827-847.

Giraldo, O. F., \& McCune, N. (2019). Can the State Take Agroecology to Scale? Public Policy Experiences in Agroecological Territorialization from Latin America. Agroecology and Sustainable Food Systems, 43(7-8), 785-809.

Giraldo, O. F., \& Rosset, P. M. (2018). Agroecology as a Territory in Dispute: Between Institutionality and Social Movements. The Journal of Peasant Studies, $45(3), 545-564$.

Global Witness. (2018). At What Cost? Irresponsible Business and the Murder of Land and Environmental Defenders in 2017.

Goyes, D. R., \& South, N. (2016). Land-grabs, Biopiracy and the Inversion of Justice in Colombia. The British Journal of Criminology, 56(3), 558-577.

Intriago, R., Gortaire Amézcua, R., Bravo, E., \& O’Connell, C. (2017). Agroecology in Ecuador: Historical Processes, Achievements, and Challenges. Agroecology and Sustainable Food Systems, 41(3-4), 311-328.

Isgren, E., \& Ness, B. (2017). Agroecology to Promote Just Sustainability Transitions: Analysis of a Civil Society Network in the Rwenzori Region, Western Uganda. Sustainability, 9(8), 1357.

Laforge, J. M. L., Anderson, C. R., \& McLachlan, S. M. (2016). Governments, Grassroots, and the Struggle for Local Food Systems: Containing, Coopting, Contesting and Collaborating. Agriculture and Human Values, 34(3), 663-681.

Levidow, L. (2015). European Transitions Towards a Corporate-environmental Food Regime: Agroecological Incorporation or Contestation? Journal of Rural Studies, 40, 76-89.

Levidow, L., Pimbert, M., \& Vanloqueren, G. (2014). Agroecological Research: Conforming - or Transforming the Dominant Agro-Food Regime? Agroecology and Sustainable Food Systems, 38(10), 1127-1155.

Loconto, A. M., \& Fouilleux, E. (2019). Defining Agroecology. The International Journal of Sociology of Agriculture and Food, 25(2), 116-137.

Meek, D., \& Anderson, C. R. (2020). Scale and the politics of the Organic Transition in Sikkim, India. Agroecology and Sustainable Food Systems, 1-20. https://doi.org/10.1080/21683565.2019.1701171.

Mier y Terán Giménez Cacho, M., Giraldo, O. F., Aldasoro, M., Morales, H., Ferguson, B. G., Rosset, P., et al. (2018). Bringing Agroecology to Scale: Key Drivers and Emblematic Cases. Agroecology and Sustainable Food Systems, 42(6), 637-665.

Miewald, C., Ostry, A., \& Hodgson, S. (2013). Food Safety at the Small Scale: The Case of Meat Inspection Regulations in British Columbia's Rural and Remote Communities. Journal of Rural Studies, 32, 93-102.

Milgroom, J., \& Spierenburg, M. (2008). Induced Volition: Resettlement from the Limpopo National Park, Mozambique. Journal of Contemporary African Studies, 26(4), 435-448. 
Peschard, K., \& Randeria, S. (2020). 'Keeping seeds in our hands': The Rise of Seed Activism. The Journal of Peasant Studies, 47(4), 613-647.

Petersen, P., Mussoi, E. M., \& Dal Soglio, F. (2013). Institutionalization of the Agroecological Approach in Brazil: Advances and Challenges. Agroecology and Sustainable Food Systems, 37(1), 103-114.

Pimbert, M. P. (2015). Agroecology as an Alternative Vision to Conventional Development and Climate-Smart Agriculture. Development, 58(2), 286-298.

Schiller, K., Godek, W., Klerkx, L., \& Poortvliet, P. M. (2019). Nicaragua's Agroecological Transition: Transformation or Reconfiguration of the Agrifood Regime? Agroecology and Sustainable Food Systems, 44, 1-18.

Schot, J., \& Geels, F. W. (2008). Strategic Niche Management and Sustainable Innovation Journeys: Theory, Findings, Research Agenda, and Policy. Technology Analysis \& Strategic Management, 20(5), 537-554.

Sherwood, S., Arce, A., \& Paredes, M. (2018). Affective Labor's 'unruly edge': The Pagus of Carcelen's Solidarity \& Agroecology Fair in Ecuador. Journal of Rural Studies, 61, 302-313.

Smith, A., \& Raven, R. (2012). What Is Protective Space? Reconsidering Niches in Transitions to Sustainability. Research Policy, 41(6), 1025-1036.

Tom, K. (2020). Speech at U.S. Department of Agriculture's (USDA) 2020 Agricultural Outlook Forum.

van der Ploeg, J. D. (2018). The New Peasantries: Rural Development in Times of Globalization. Earthscan Food and Agriculture.

Wallace, R. (2016). Big Farms Make Big Flu: Dispatches on Influenza, Agribusiness, and the Nature of Science. New York, NY: Monthly Review Press.

Wise, T. (2020). False Promises: The Alliance for a Green Revolution in Africa (AGRA). https://www.rosalux.de/fileadmin/rls_uploads/pdfs/Studien/ False_Promises_AGRA_en.pdf

Open Access This chapter is licensed under the terms of the Creative Commons Attribution 4.0 International License (http://creativecommons.org/licenses/ by $/ 4.0 /)$, which permits use, sharing, adaptation, distribution and reproduction in any medium or format, as long as you give appropriate credit to the original author(s) and the source, provide a link to the Creative Commons licence and indicate if changes were made.

The images or other third party material in this chapter are included in the chapter's Creative Commons licence, unless indicated otherwise in a credit line to the material. If material is not included in the chapter's Creative Commons licence and your intended use is not permitted by statutory regulation or exceeds the permitted use, you will need to obtain permission directly from the copyright holder.

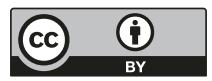

